\title{
Surgical resection for pelvic retroperitoneal Castleman's disease: A case report and review literature
}

\author{
MASATOSHI KITAKAZE, NORIKATSU MIYOSHI, SHIKI FUJINO, TAKAYUKI OGINO, HIDEKAZU TAKAHASHI, \\ MAMORU UEMURA, TSUNEKAZU MIZUSHIMA, YUICHIRO DOKI and HIDETOSHI EGUCHI
}

Department of Gastroenterological Surgery, Osaka University, Osaka 5650871, Japan

Received September 1, 2020; Accepted November 30, 2020

DOI: 10.3892/br.2021.1405

\begin{abstract}
Castleman's disease (CD) is a rare atypical lymphoproliferation disorder first reported in 1954. Clinically, CD is classified as unicentric or multicentric $\mathrm{CD}$ based on anatomical distribution. Unicentric CD primarily affects the mediastinum, and rarely affects the retroperitoneal location. The standard treatment for unicentric CD is complete surgical resection; however, this can be complicated by a high degree of attachment with other organs or hypervascularity. Preoperative angiography and embolization of the arteries that feed the problematic mass can reduce intraoperative bleeding in cases of $\mathrm{CD}$ with hypervascularity. In the present case report, a 44-year-old man who was found to have a pelvic retroperitoneal mass with calcification based on abdominal imaging results is discussed. Due to the hypervascularity of the mass, preoperative embolization was performed. The mass was completely resected without any complications. Additionally, a review of the literature on pelvic $\mathrm{CD}$ and preoperative embolization of $\mathrm{CD}$ was performed to provide an up-to-date reference on the management and outcomes of patients with CD.
\end{abstract}

\section{Introduction}

Castleman disease (CD) is a rare atypical lymphoproliferation disorder, also known as angiofollicular hyperplasia (1). CD was first reported by Benjamin Castleman in 1954 and defined 1956 (2). Clinically, CD is classified as unicentric or multicentric CD based on the anatomical distribution (3). Unicentric CD primarily affects the mediastinum, and rarely affects the retroperitoneal or pelvic locations (4). The standard treatment for unicentric CD is complete surgical resection (5). However, in some cases, it may not be possible to resect the problematic mass due to a high degree of attachment with other

Correspondence to: Dr Norikatsu Miyoshi, Department of Gastroenterological Surgery, Osaka University, 2-2 (E2) Yamadaoka, Suita, Osaka 5650871, Japan

E-mail: nmiyoshi@gesurg.med.osaka-u.ac.jp

Key words: Castleman's disease, unicentric, hyaline-vascular type, pelvic, surgery, embolization organs or hypervascularity (6). Preoperative angiography and embolization of the arteries that feed the problematic mass can reduce intraoperative bleeding in cases of $C D$ with hypervascularity (7).

In the present case report, a rare case of unicentric CD presented as a pelvic retroperitoneal mass. Due to the hypervascularity of the mass, preoperative embolization was performed. The mass was completely resected without any complications. Additionally, a review of the literature on pelvic CD and preoperative embolization of $\mathrm{CD}$ was performed to provide an up-to-date reference on the management and outcomes of patients with $\mathrm{CD}$.

\section{Case report}

A 44-year-old man presented with a history of diarrhea at another hospital. He was diagnosed with acute enteritis with computed tomography (CT), and the diarrhea was relieved after a few days. The CT scan incidentally revealed a pelvic retroperitoneal mass with calcification, and he was referred to Osaka University Hospital. The patient underwent appendectomy for appendicitis 30 years ago, and had no viral infection or history of any other diseases. The pelvic calcification was previously identified in previous abdominal X-rays, but further examination was not performed. Physical examination revealed no abnormal symptoms. Laboratory blood tests, including for tumor makers (CA19-9 and carcinoembryonic antigen) were normal. Any abnormal finding was not detected by colonoscopy. The abdominal contrast-enhanced CT scan revealed a well-defined $50 \times 30 \mathrm{~mm}$ mass behind the sigmoid mesenteric, under the bifurcation of the aorta in the pelvic retroperitoneal. Non-enhanced phase imaging revealed coarse calcification inside the mass, and evident contrast enhancement was observed in the mass during the arterial phase (Fig. 1). Magnetic resonance imaging (MRI) also revealed a well-defined $50 \times 30 \mathrm{~mm}$ solid mass situated in the pelvic retroperitoneal. The mass demonstrated heterogeneous and moderately hyperintense signal intensity, and the low signal intensity corresponded to calcification in the T2-weighed images and diffusion-weighted images (Fig. 2). A positive emission tomography/CT scan was performed to exclude the possibility of paraneoplastic manifestations of a primary tumor, and it revealed a 50x30 mm space-occupying lesion with hypermetabolic activity (SUVmax at 4.1) (Fig. 3). 


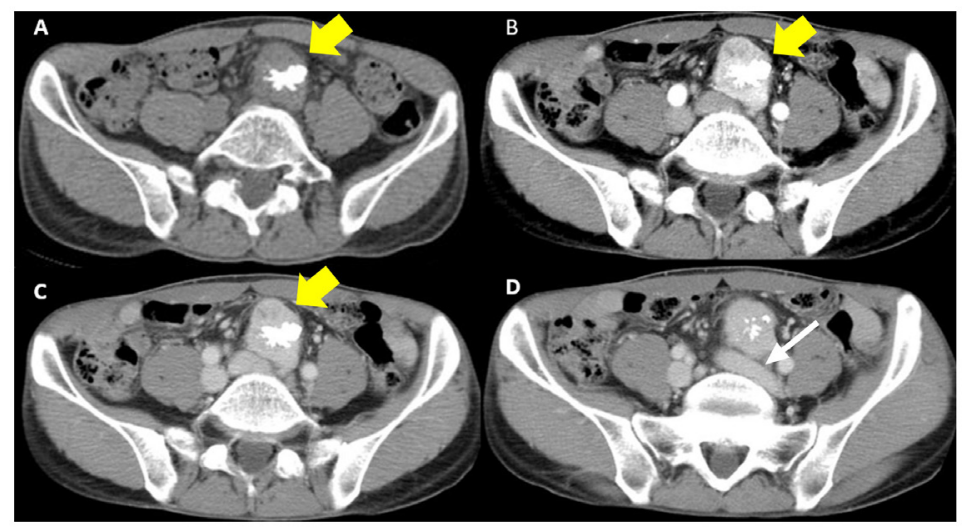

Figure 1. Abdominal and pelvic contrast-enhanced CT findings. (A) CT scan in the non-enhanced phase. The yellow arrow shows the 50x30 mm, well-defined mass with calcification under the bifurcation of the aorta in pelvic retroperitoneal. (B) CT scan in the arterial phase. The imaging revealed an evident contrast enhancement mass. (C and D) CT scan in the venous phase. The white arrow shows the mass is close to left common iliac vein. CT, computed tomography.

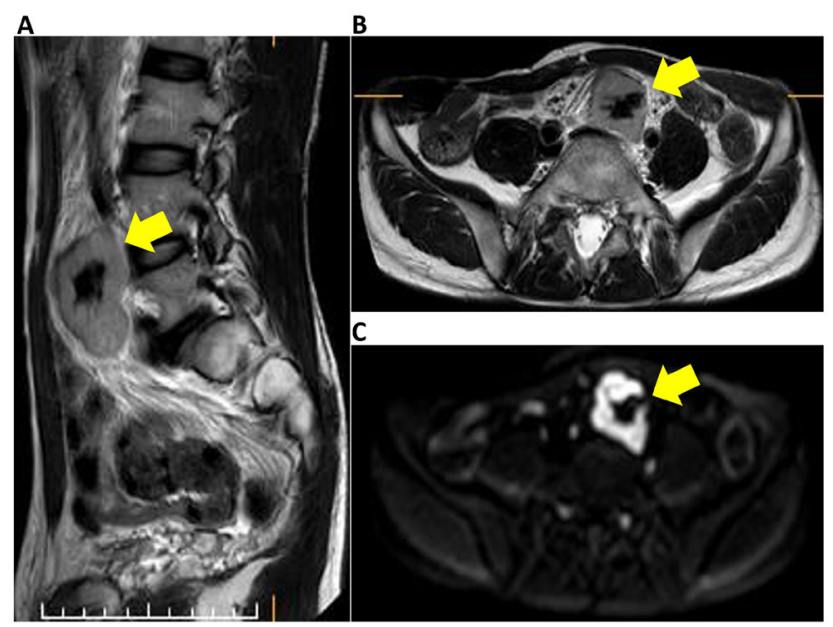

Figure 2. Pelvic MRI findings. (A) MRI sagittal T2; the arrow shows the $50 \mathrm{~mm}$ solid mass with high intensity. (B) MRI axial T2; the arrow points to the high intensity mass with a low intensity lesion. (C) MRI axial diffusion weighted image. The arrow points the mass with high intensity. MRI, magnetic resonance imaging.

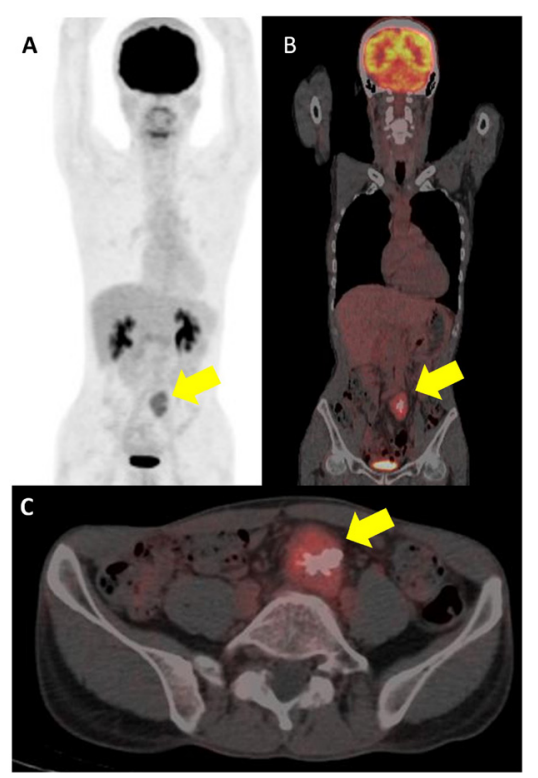

Figure 3. PET CT scan findings. (A and B) PET CT scan sagittal. (C) PET CT scan axial; the arrow shows the $50 \times 30 \mathrm{~mm}$ space-occupying lesion with hypermetabolic activity (SUVmax at 4.1) in the pelvic retroperitoneal. PET CT, positron emission tomography computed tomography.
Possible differential diagnosis based on the images were $\mathrm{CD}$, primary mesenteric gastrointestinal stromal tumor or leiomyoma. At first, a diagnosis of $\mathrm{CD}$ was doubted as the tumor had calcification, exhibited a strong contrast in imaging, had an uniform edge and a relatively uniform inside on the abdominal CT scan; the tumor was generally isointense on T1 weighted images and hyperintense on T2 images (8). Surgical resection following embolization was suggested. Angiographically, the tumor was hypervascular with a dense capillary blush, and it was supplied by the middle sacral artery (Fig. 4). The vasculature of the mass was embolized by DMSO and the patient was operated on the following day.

During the laparotomy, the mass was located at the bifurcation of the aorta behind the sigmoid mesentery. Mobilization of the sigmoid mesentery revealed that the mass was $50 \times 30 \mathrm{~mm}$ in size, rubbery, rich in vasculature and exhibited a high-degree of attachment to the left common iliac vein. Following surgical ligation and dissection of the vasculature to the mass, the mass was completely resected from the adjacent organs without any complications. The patient lost $160 \mathrm{ml}$ of blood, but no blood transfusion was required. The excised mass was round, well circumscribed and encapsulated. The cut surface was dark red with a central 


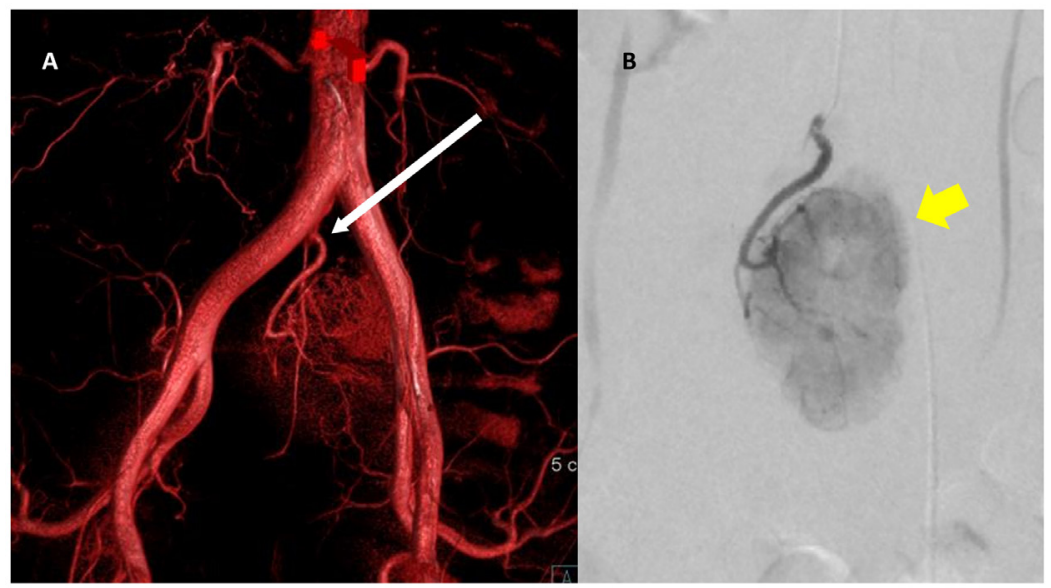

Figure 4. Angiography findings. (A and B) The yellow arrow shows the mass with a dense capillary blush. The mass was supplied by the middle sacral artery (white arrow).

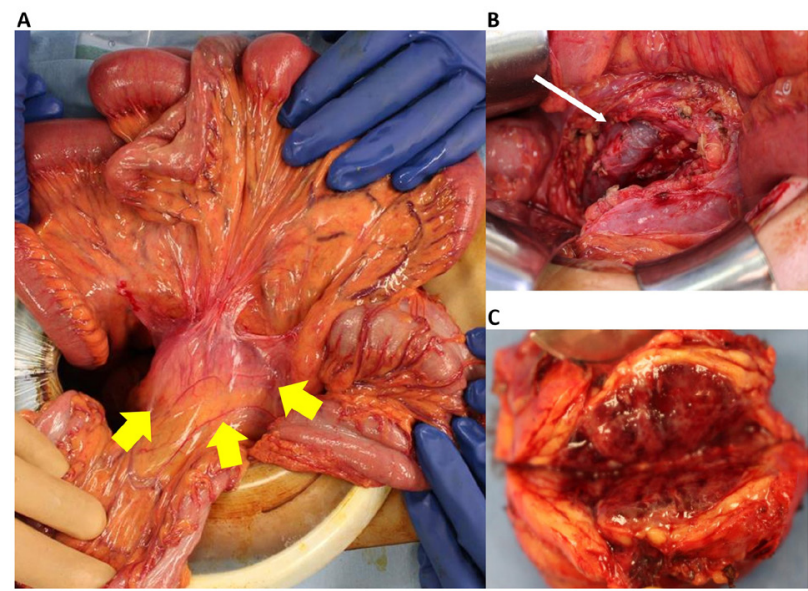

Figure 5. Intraoperative findings. (A) The yellow arrow shows the mass behind the sigmoid mesenteric. (B) After resection of the mass. The mass exhibited a high degree of attachment to the left common iliac vein (white arrow). (C) Resected specimen; the mass was 50x30 mm in size, round, rubbery, well circumscribed and encapsulated. The cut surface was dark red with a central white zone of fibrosis and calcification, and had a granular appearance.

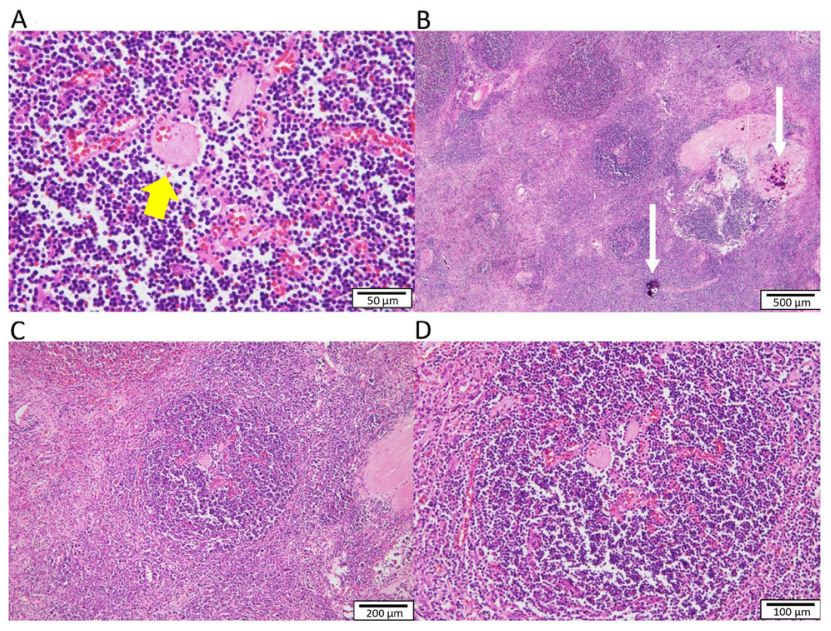

Figure 6. Histopathological findings of the resected specimen. (A and B) Histopathological examination revealed the lymphoid tissue had a hyalinized vasculature (yellow arrow), calcification (white arrow) and noticeable hemorrhaging. (C and D) A germinal center was not observed.

white zone of fibrosis and calcification, and it had a granular appearance (Fig. 5). Histopathological examination revealed the lymphoid tissue had a hyalinized vasculature, calcification and noticeable hemorrhaging. Furthermore, a germinal center was not observed, and thus germinal center atrophy was suspected (Fig. 6). Immunohistochemical analysis showed protein expression of 


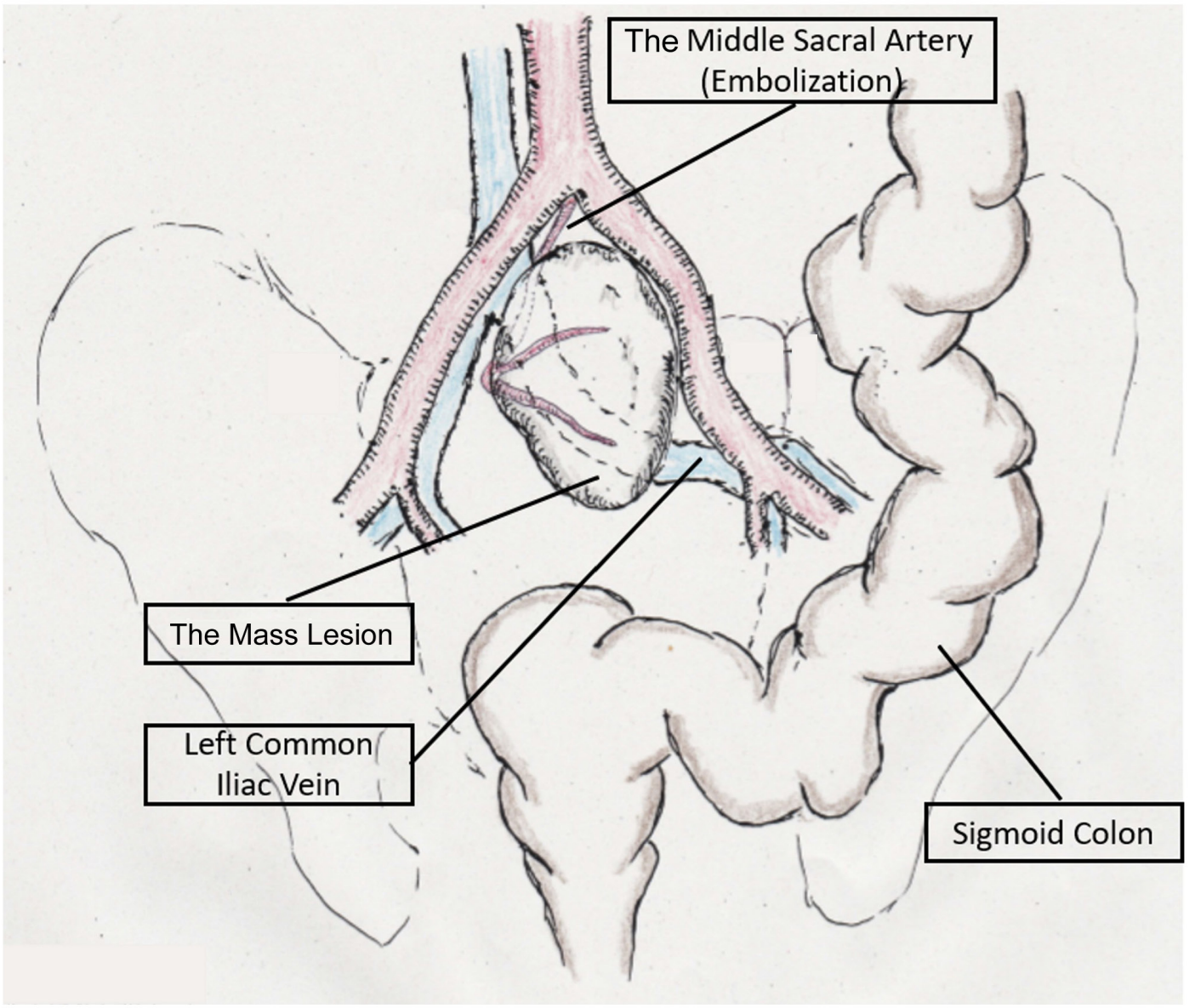

Figure 7. Schema of the present case. The arrow shows the mass was present under the bifurcation of the aorta in the pelvic retroperitoneal and was supplied by the middle sacral artery (dotted arrow) embolized preoperatively.

CD3, CD20 and CD79a. Immunohistochemistry did not show an increase in IgG4 antibody expression compared with total immunoglobulin expression. Clonality analysis using genomic DNA extraction from the surgical specimen showed no clonality and DNA fragmentation. These histological findings suggested $\mathrm{CD}$ of a hyaline vascular (HV) type. Currently, at 20 months post-operation, the patient has not experienced a recurrence. A schematic of this case is shown (Fig. 7).

\section{Discussion and literature review}

The classification of CD into unicentric or multicentric CD is based on the presence of this lymphoproliferative disorder in one or more regions, respectively (9). There are three histopathological types of the disease, HV, plasmacytic (PC) and mixed type (10). HV type occurs in $80-90 \%$ of cases and usually appears more frequently as a unicentric localization, whereas PC is primarily multicentric and accounts for $10-20 \%$ of cases (11). Furthermore, $90 \%$ of patients with unicentric CD are usually asymptomatic (1). The large lymph node due to unicentric CD is located only at a single site, exhibits slow progression and is rarely observed in radiographs (1). CD is often overlooked as a possible diagnosis due to its low incidence rate. The possibility of $\mathrm{CD}$ should be considered following the identification of a homogeneous vascular mass (8). CD most commonly affects the mediastinum $(63 \%)$, followed by the abdomen (11\%), retroperitoneum (7\%) and axilla (4\%) (12).
Unicentric CD in the retroperitoneum is commonly found in the retroperitoneal space $(53 \%)$, followed by the pararenal (15\%), peripancreatic $(9.7 \%)$ and pelvic regions $(6.7 \%)$ (4). The most common presentation is abdominal pain (42\%) (13). Due to its rarity and lack of disease-specific makers and indications, preoperative diagnosis is difficult. The differential diagnosis includes lymphoma, sarcoma, lymph node metastasis, gastrointestinal stromal tumor, lipomas, leiomyomas, neurofibromas, paraganglioma and infectious/inflammatory diseases (14). The imaging findings of unicentric CD are commonly seen on contrast-enhanced CT as a well-defined, solitary soft tissue tumor with evident contrast enhancement during the arterial phase (12). Most unicentric CD lesions are isointense or slightly hyperintense relative to skeletal muscle on T1-weighted images, and hyperintense on T2-weighted images, reflecting the vascularity of the mass (15). The first choice of treatment for unicentric CD is surgical resection if it is curatively resectable; the 10-year overall survival rate is $95 \%$ and the 5-year disease-free survival rate is over $90 \%$, suggesting a good prognosis following complete resection (16).

All previously reported cases of abdominal, retroperitoneal and pelvic unicentric CD were searched in PubMed, focusing on studies published in English with images to support the location of the masses identified. A total of 152 cases of abdominal, retroperitoneal and pelvic unicentric $\mathrm{CD}$ were found (as of July 2020). A summary of the areas of the abdomen where 


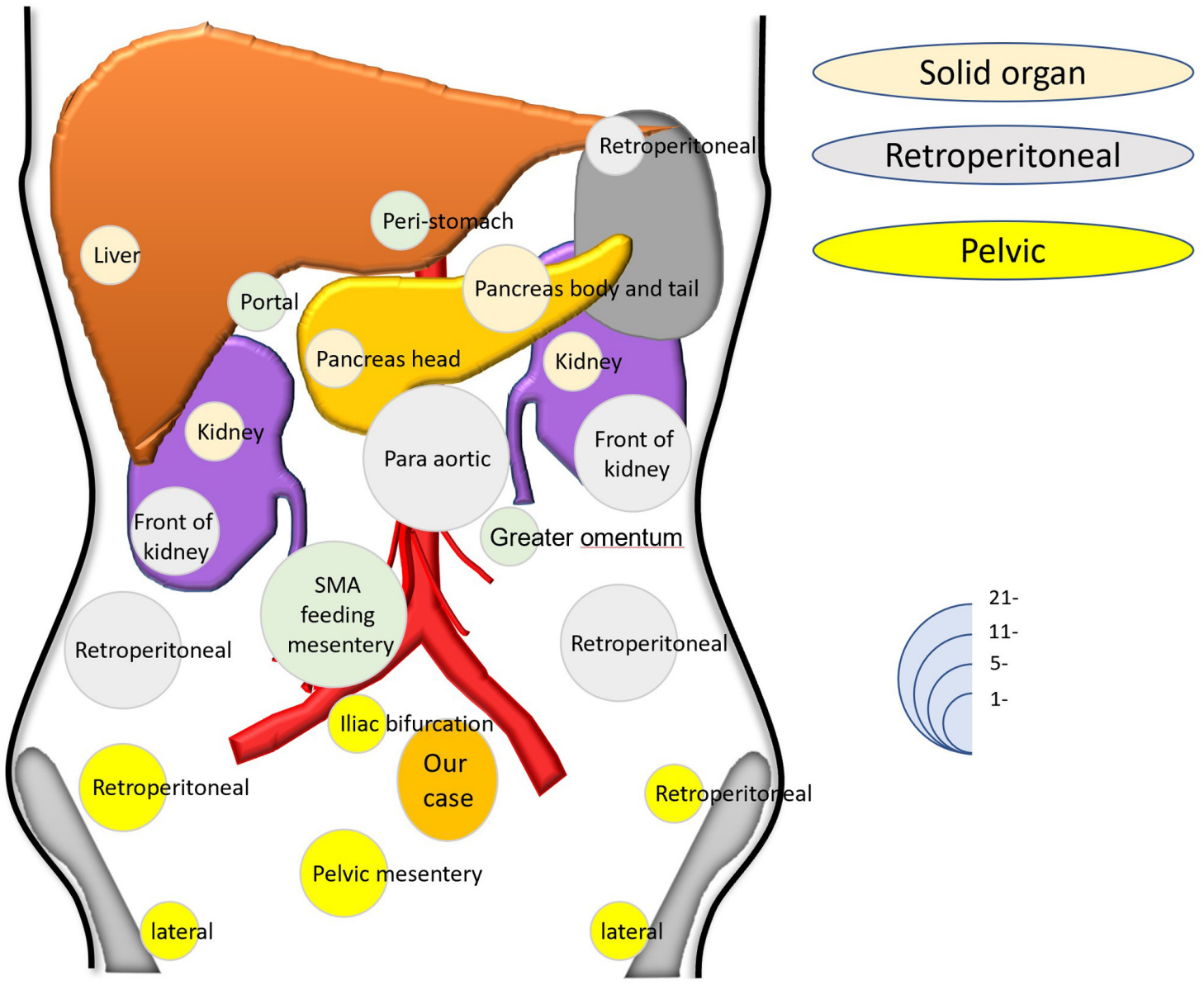

Figure 8. A literature review of abdominal unicentric $\mathrm{CD}$ ( $\mathrm{n}=152$ cases). The size of the circles indicates the number of cases associated with that region/organ. The present case is shown in an oval shape.

unicentric $\mathrm{CD}$ has been reported is shown in Fig. 8. The most frequently reported site was the superior mesenteric artery feeding mesentery $(25 \% ; 38 / 152)$. In the retroperitoneal, the paraaortic and left peri-renal areas were found to be the most common: $13.8 \%$ (21/152) and 11.2\% (17/152), respectively. A small number of cases have also been reported in solid organs such as the liver, pancreas and kidneys (17-19). Pelvic unicentric CD occurred less frequently than intra-abdominal or extra pelvic retroperitoneal unicentric CD, accounting for $15.1 \%$ $(25 / 152)$ cases of abdominal unicentric CD.

Intraabdominal presentations of $\mathrm{CD}$ were the second most common location, and pelvic presentations were rare. The present case report was compared with other reported cases in which unicentric $\mathrm{CD}$ was present as a pelvic mass. There were 10 cases, and the clinical data and surgical outcomes of these patients are reviewed and listed in Table I. The mean age of the patients was 35.4 years, and the mean greatest diameter of the lesion was $5.88 \mathrm{~cm}$. HV type was observed in 10 out of 11 cases. Furthermore, 2 cases were treated using a laparoscopic approach. All cases in Table I were treated with complete resection and there were no cases of recurrence. Unicentric CD with calcification was found in 2 cases in Table I. The case reported in the present study was the only case in which calcifications were present, and was resected after embolization for pelvic CD.

Several previous cases were diagnosed with abdominal unicentric CD following post-surgical histological examination.
The optimal therapy for unicentric CD is surgical resection, which is usually curative if the disease is amenable to complete resection (5). Surgical resection is a useful approach for the diagnosis and treatment of the disease (8).

The masses found in patients with CD often exhibit a moderate to high degree of attachment contiguous with surrounding anatomical structures (6). A high degree of attachment to the contiguous anatomical structures is often observed in lesions $>5 \mathrm{~cm}$ in diameter (6). Furthermore, significant bleeding may obstruct surgical procedures (4).

In cases of HV-type CD where there is a notably higher risk of massive bleeding due to the hypervascularity, preoperative angiography and embolization of the arteries that supply the tumor should be considered to reduce intraoperative bleeding (7). Preoperative embolization has also been suggested where there is encasement or invasion of the adjacent structures (20-22).

The present case was compared with the other reported cases in which patients with unicentric CD were treated using complete surgical resection after angiography and embolization of the feeding artery. There were 10 such cases, and the clinical data and surgical outcomes of these patients were reviewed and are listed in Table II. The mean age of the patients was 28.6 years and the mean greatest diameter of the lesion was $8.58 \mathrm{~cm}$. HV type was observed in 10 of 11 cases (aforementioned 10 cases and the present case; Table II) The mean blood loss during operation ranged from minimal to $940 \mathrm{ml}$, and the clinical course 


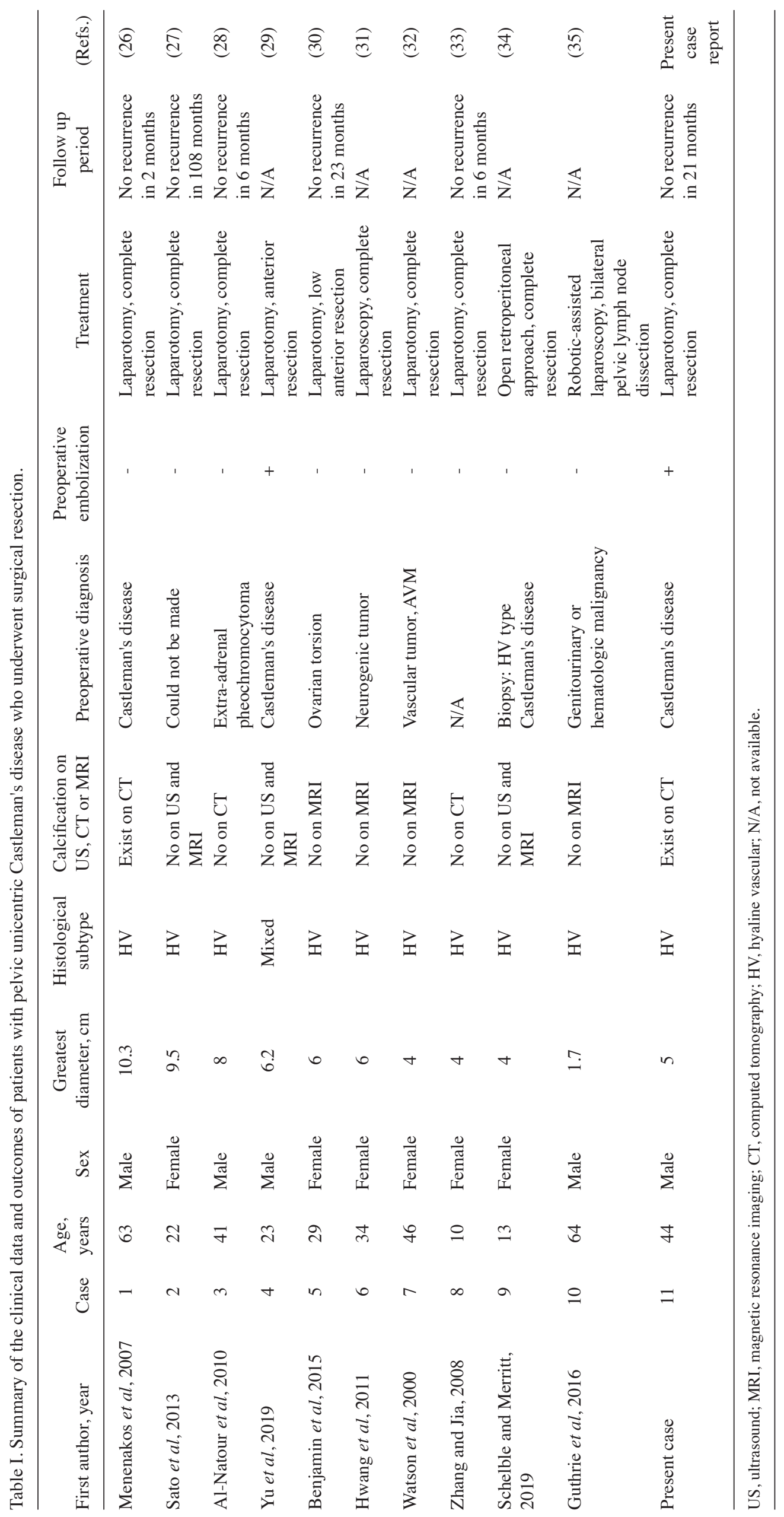




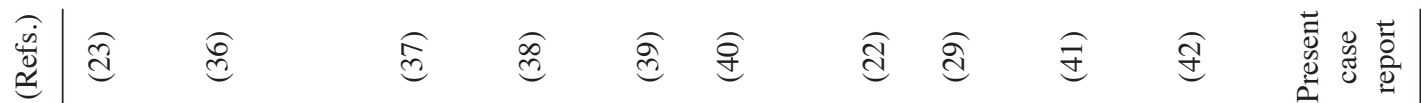

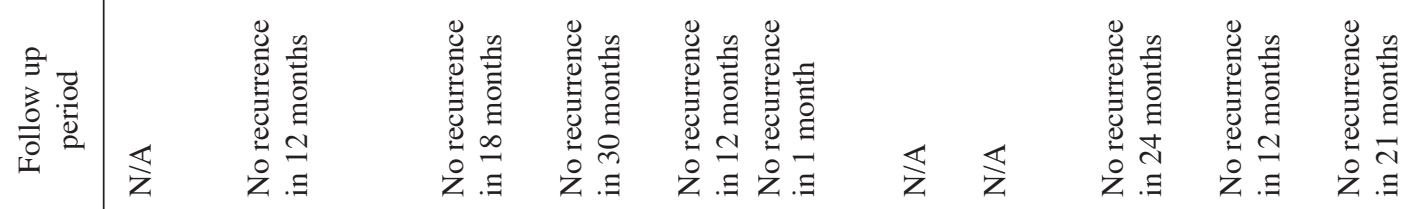

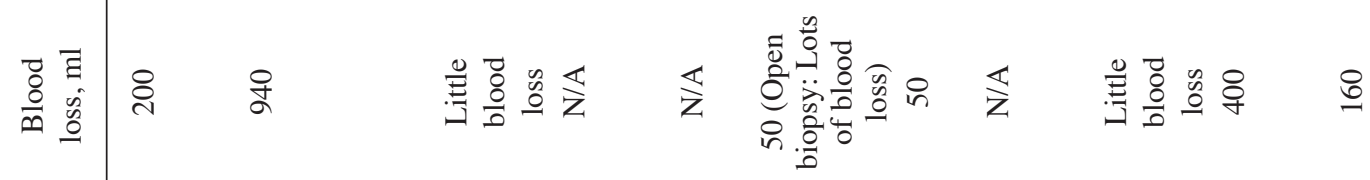

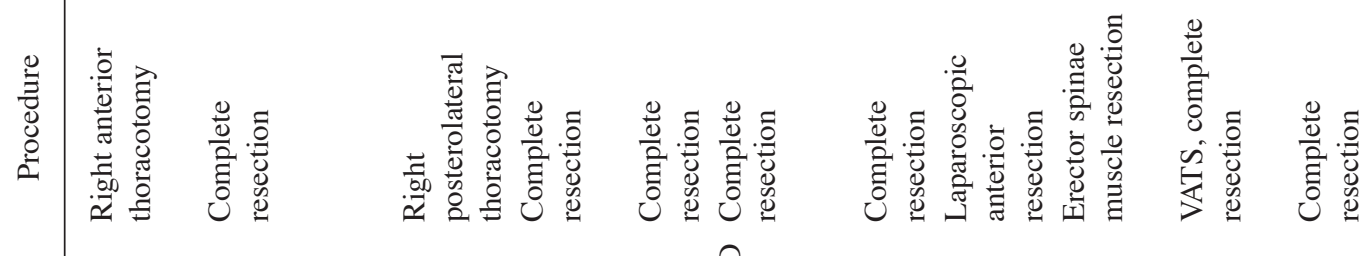

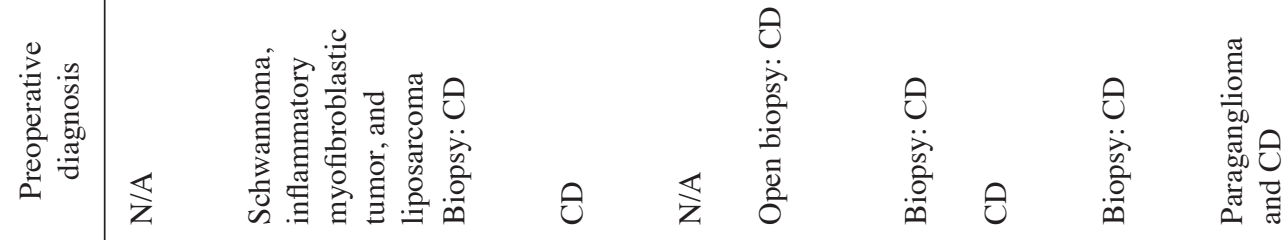

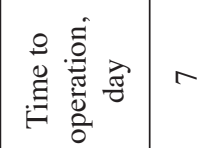

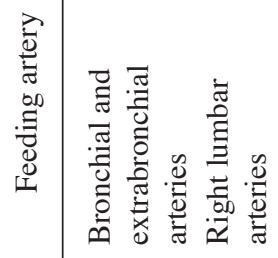

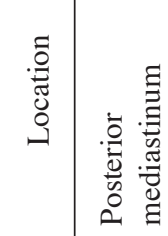

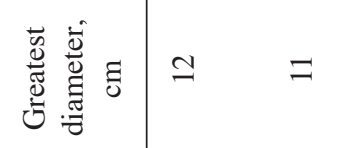

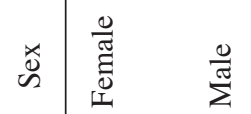

密 $\bar{\infty}$

惫

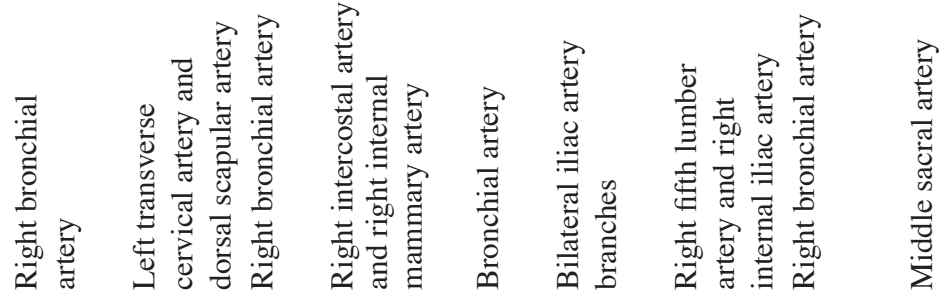

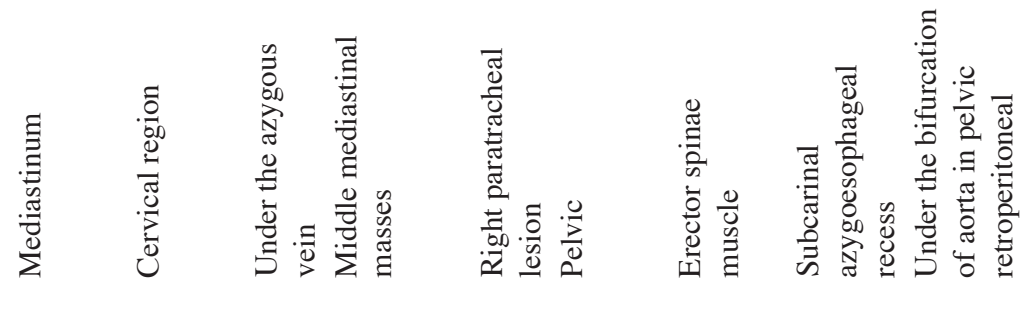

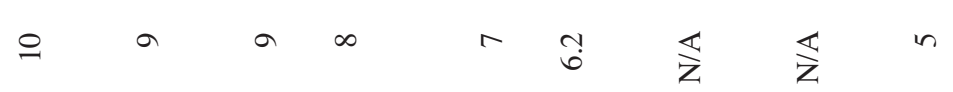

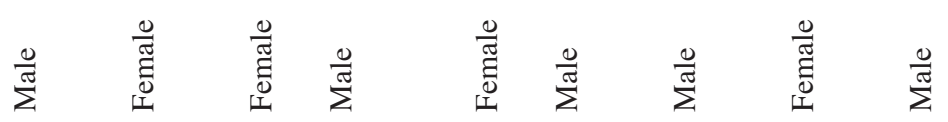

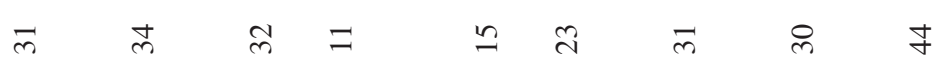

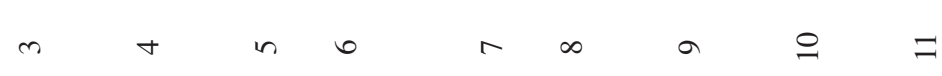

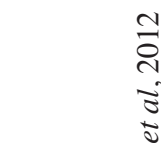

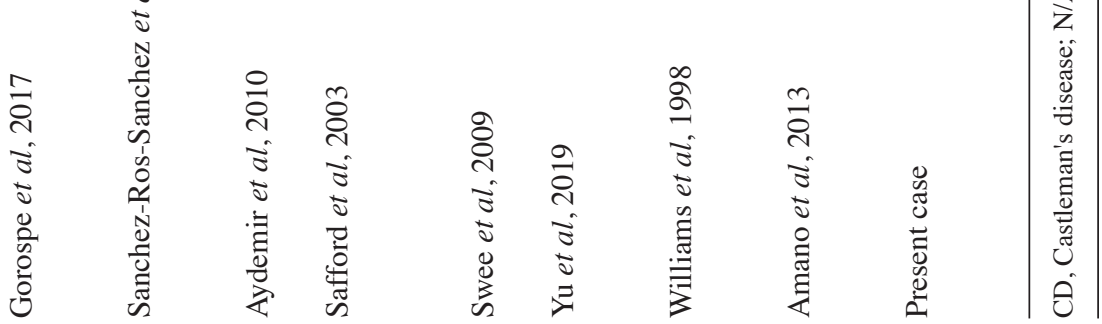


was uneventful in all cases (Table II). Preoperative embolization may affect the histological findings on the resected specimens. In relation to the histological findings after embolization, fibrosis and marked hemorrhage were reported.

In the present case, the patient had previously been shown to possess a pelvic calcification in an abdominal $x$-ray. It has been reported that calcifications are seen in $31 \%$ of patients with abdominal or pelvic CD (23). Pelvic calcifications are usually indicative of neurogenic tumors, teratomas, uterine fibroids and intravesical stones, amongst other potential conditions $(24,25)$. However, it is important to consider the possibility of pelvic CD in the differential diagnosis of a pelvic calcification in an abdominal X-ray.

In conclusion, $\mathrm{CD}$ is a rare lymphoproliferation disorder of uncertain etiology. Pelvic CD is extremely rare, so it is important to consider CD as a differential diagnosis when a pelvic lesion is found. Although the clinical course of complete surgical resection for unicentric CD is good, surgical resection may be difficult due to attachment with the surrounding tissues or high hypervascularity. Preoperative angiography and embolization of the arteries feeding the tumor can prevent or limit intraoperative bleeding.

\section{Acknowledgements}

Not applicable.

\section{Funding}

No funding was received.

\section{Availability of data and materials}

All data generated and/or analyzed in the present study are included in this published article.

\section{Authors' contributions}

MK, NM, SF, TO, HT, MU, TM, YD and HE contributed to the diagnosis at the preoperative conference, NM and SF performed the resection, and contributed to the follow-up. All authors read and approved the final manuscript.

\section{Ethics approval and consent to participate}

Not applicable.

\section{Patient consent for publication}

Written informed consent was obtained from the patient for the publication of this case report and the accompanying images.

\section{Competing interests}

The author declare that they have no competing interests.

\section{References}

1. Ren N, Ding L, Jia E and Xue J: Recurrence in unicentric Castleman's disease postoperatively: A case report and literature review. BMC Surg 18: 1, 2018.
2. Castleman B, Iverson L and Menendez VP: Localized mediastinal lymphnode hyperplasia resembling thymoma. Cancer 9: 822-830, 1956

3. Li XF, Liu JZ, Zhang CJ and Miao Q: Unicentric Castleman's disease with Cardiovascular Involvement. Chin Med Sci J 32: 198-200, 2017.

4. Gopi P, Potty VS, Kaurav RS and Govindan K: Unicentric Castleman's disease as a localized retroperitoneal mass: A case report and review of literature. Int $\mathbf{J}$ Appl Basic Med Res 8: 259-262, 2018.

5. Soumerai JD, Sohani AR and Abramson JS: Diagnosis and management of Castleman disease. Cancer Control 21: 266-278, 2014.

6. Ko SF, Ng SH, Hsieh MJ, Lin JW, Huang CC, Lee TY and Chen WJ: Castleman disease of the pleura: Experience with eight surgically proven cases. Ann Thorac Surg 76: 219-224, 2003.

7. Madan R, Chen J-H, Trotman-Dickenson B, Jacobson F and Hunsaker A: The spectrum of Castleman's disease: Mimics, radiologic pathologic correlation and role of imaging in patient management. Eu J Radiol 81: 123-131, 2012.

8. Tampakis A, Tampaki EC, Daikeler T and Lardinois D: Intrathoracic tumor of the chest wall: A case of Castleman's disease mimicking myositis of the lower extremities. Gen Thorac Cardiovasc Surg 65: 664-666, 2017.

9. Svensson JF, Marshall-Heyman M, Lindgren F and Ghaffarpour N: Minimal access surgery in Castleman disease in a child, a case report. J Pediatr Surg Case Rep 3: 289-291, 2015.

10. Bracale U, Pacelli F, Milone M, Bracale UM, Sodo M, Merola G, Troiani T and Di Salvo E: Laparoscopic treatment of abdominal unicentric Castleman's disease: A case report and literature review. BMC Surg 17: 38, 2017.

11. Xu J, Zhou BO, Cao HL, Wang BO, Yan S and Zheng SS: Surgical management of isolated retroperitoneal Castleman's disease: A case report. Oncol Lett 11: 2123-2126, 2016.

12. Bucher P, Chassot G, Zufferey G, Ris F, Huber O and Morel P: Surgical management of abdominal and retroperitoneal Castleman's disease. World J Surg Oncol 3: 33, 2005.

13. Vassos N, Raptis D, Lell M, Klein P, Perrakis A, Köhler J, Croner RS, Hohenberger W and Agaimy A: Intra-abdominal localized hyaline-vascular Castleman disease: Imaging characteristics and management of a rare condition. Arch Med Sci 12: 227-232, 2016.

14. Jiang Y, Hou G, Zhu Z, Huo L, Li F and Cheng W: The value of multiparameter ${ }_{18} \mathrm{~F}$-FDG PET/CT imaging in differentiating retroperitoneal paragangliomas from unicentric Castleman disease. Sci Rep 10: 12887, 2020.

15. Wong RSM: Unicentric Castleman disease. Hematol Oncol Clin North Am 32: 65-73, 2018.

16. Talat N, Belgaumkar AP and Schulte KM: Surgery in Castleman's disease: A systematic review of 404 published cases. Ann Surg 255: 677-684, 2012.

17. Masoum SHF, Nooghabi AJ and Rezaei R: Castleman's disease: Report of four cases and review of the literature. Acta Medica Iranica 56: 132-136, 2018

18. Goetze O, Banasch M, Junker K, Schmidt WE and Szymanski C: Unicentric Castleman's disease of the pancreas with massive central calcification. World J Gastroenterol 11: 6725-6727, 2005.

19. Miyoshi H, Mimura S, Nomura T, Tani J, Morishita A, Kobara H, Mori H, Yoneyama H, Deguchi A, Himoto T, et al: A rare case of hyaline-type Castleman disease in the liver. World J Hepatol 5: 404-408, 2005

20. Jang SM,Han H, Jang KS, Jun YJ,Lee TY and Paik SS: Castleman's disease of the renal sinus presenting as a urothelial malignancy: A brief case report. Korean J Pathol 46: 503-506, 2012.

21. Husainy MA, Sayyed F and McPherson SJ: Castleman's disease: A rare indication for endovascular therapy for hemoptysis. Indian J Radiol Imaging 27: 33-35, 2017.

22. Swee W, Housseini AM, Angle JF, Jones DR, Daniel TM, Turba UC, Abdel-Gawad EA and Hagspiel KD: Preoperative embolization of Castleman's disease using microspheres. Ann Thorac Surg 88: 1999-2001, 2009.

23. Robert JH, Sgourdos G, Kritikos N, Didier D and Terraz S: Preoperative embolization of hypervascular Castleman's disease of the mediastinum. Cardiovasc Interven Radiol 31: 186-188, 2008.

24. Meador TL and McLarney JK: CT features of Castleman disease of the abdomen and pelvis. Am J Roentgenol 175: 115-118, 2000.

25. Sadamoto Y, Abe Y, Higuchi K, Kato K, Matsumoto S, Arima N and Nawata H: Retroperitoneal Castleman's disease of the hyaline vascular type presenting arborizing calcificatio. Intern Med 37: 691-693, 1998. 
26. Menenakos C, Braumann C, Hartmann J and Jacobi CA Retroperitoneal Castleman's tumor and paraneoplastic pemphigus: Report of a case and review of the literature. World J Surg Oncol 5: 45, 2007.

27. Sato A: Castleman's disease in the pelvic retroperitoneum: A case report and review of the Japanese literature. Int J Surg Case Rep 4: 19-22, 2013.

28. Al-Natour S, Sawalhi S, Al-Muhtady D and Hijazi E: Mesenteric Castleman's disease: Case report and literature review. Asian J Surg 33: 150-153, 2010.

29. Yu G, Cao F, Gong H, Liu P, Sun G and Zhang W: Embolization of blood-supply artery followed by surgery for treatment of mesorectal Castleman's disease: Case report and literature review. Gastroenterol Rep 7: 141-145, 2019.

30. Benjamin B, Zaltzman R, Shpitz B, Gordon CR and Avital S: Presacral mass discovered during pregnancy followed by myasthenia gravis. Isr Med Assoc J 17: 318-320, 2015.

31. Hwang MR, Chang HJ, Kim MJ, Seo GJ, Yoo SB, Park JW, Choi HS and Oh JH: Castleman's disease of the mesorectum: Report of a case. Surg Today 41: 271-275, 2011.

32. Watson G, Keane A and Chawdhery Z: Pelvic Castleman's disease shown by angiography and MRI. Eur Radiol 10: 1837-1839, 2000.

33. Zhang KR and Jia HM: Mesenteric Castleman disease. J Pediatr Surg 43: 1398-1400, 2008.

34. Schelble AP and Merritt DF: Pelvic Castleman's disease presenting as an adnexal mass in an adolescent. J Pediatr Adolesc Gynecol 32: 86-89, 2019.

35. Guthrie PJ, Thomas JV, Peker D, Turkbey B and Rais-Bahrami S: Perivesical unicentric Castleman disease initially suspected to be metastatic prostate cancer. Urol Annals 8: 245-248, 2016.
36. Nagano S, Yokouchi M, Yamamoto T, Kaieda H, Setoguchi T, Hiraki T, Tashiro Y, Yonezawa S and Komiya S: Castleman's disease in the retroperitoneal space mimicking a paraspinal schwannoma: A case report. World J Surg Oncol 11: 108, 2013.

37. Gorospe L, Valdebenito-Montecino AP and Munoz-Molina GM: Preoperative embolization of mediastinal Castleman's disease presenting with stroke. Asian Cardiovasc Thorac Ann 25: 158-159, 2017.

38. Sanchez-Ros-Sanchez A, Infante-Cossio P, Gonzalez-Garcia A and Borrero-Martin JJ: Preoperative embolization for the treatment of cervical Castleman disease. J Craniofac Surg 23 e257-e259, 2012.

39. Aydemir B, Okay T, Imamoglu O, Sahin S and Dogusoy I: Preoperative embolization in mediastinal Castleman's disease. Thorac Cardiovasc Surg 58: 496-498, 2010.

40. Safford SD, Lagoo AS and Mahaffey SA: Preoperative embolization as an adjunct to the operative management of mediastinal Castleman disease. J Pediatr Surg 38: E21-E23, 2003.

41. Williams HR, Millner PA and Coral A: Castleman's disease of the erector spinae muscle. Skel Radiol 27: 637-640, 1998.

42. Amano Y, Takai D, Ohishi N, Shinozaki-Ushiku A, Fukayama M, Akahane M, Nakajima J and Nagase T: Successful treatment of mediastinal unicentric Castleman's disease using video-assisted thoracoscopic surgery with preoperative embolization. Case Rep Med 2013: 354507, 2013.

This work is licensed under a Creative Commons Attribution-NonCommercial-NoDerivatives 4.0 International (CC BY-NC-ND 4.0) License. 